\title{
EI diario personal en la literatura concentracionaria: testimonio y ficción
}

\author{
Álvaro Luque Amo \\ Universidad de Granada \\ luqueamo@correo.ugr.es
}

Resumen: Este artículo trata de leer el diario personal desde la perspectiva de la literatura en el ámbito de los campos de concentración. La literatura concentracionaria tiene como base el relato testimonial, de tal manera que una manifestación como la diarística cobra una gran importancia en la proliferación de textos de este tipo. Desde un punto de vista teórico-literario, el artículo trata de construir, por tanto, un marco teórico que habilite el análisis de los diarios personales gestados en este contexto.

Palabras clave: diario personal; campos de concentración; literatura; teoría de la autobiografía.

\section{The personal diary in concentrationary literature: Testimony and fiction}

Abstract: This paper tries to read the personal diary from the perspective of literature in a field such as concentration camps. The concentrationary literature is based on the testimonial story, in such a way that the personal diary becomes very important in the proliferation of these types of texts. From a theoreticalliterary point of view, this paper aims to construct a theoretical frame that enables the analysis of the personal diaries gestated in this context.

Keywords: personal diary; concentration camps; literature; theory of autobiography.

/) Luque Amo, Álvaro. 2016. "El diario personal en la literatura concentracionaria: testimonio y ficción". Quaderns de Filologia: Estudis Literaris XXI: 119-134. doi: $10.7203 /$ qdfed.21.9338 



\section{La literatura concentracionaria y la autobiografía}

La relación entre autobiografía y campos de concentración es inevitable. Hablar de literatura concentracionaria, como señala Sánchez Zapatero (2011: 326), es hacerlo de un tipo de literatura que nace de una circunstancia concreta: la del Yo que presencia unos hechos y tiene la voluntad de ofrecer un testimonio de estos. En este contexto, la autobiografía se revela como la herramienta principal para dejar constancia de una existencia vivida en las inmediaciones de un hecho histórico relevante; de ahí que la mayoría del corpus concentracionario tenga un marcado carácter autobiográfico y la escritura diarística sea una de las manifestaciones más frecuentes.

En primer lugar, para entender desde dónde se parte, hace falta examinar la definición de literatura concentracionaria que sirve a estas páginas $^{1}$. Es esta, en principio, una definición que arranca de un hecho extraliterario para delimitar un fenómeno artístico y lingüístico, por lo que deberá ser entendida desde una perspectiva intercultural (Sánchez Zapatero, 2010: 45). La literatura concentracionaria no es, de este modo, un tipo de texto que se corresponda con un género literario concreto ${ }^{2}$, un movimiento artístico o incluso una generación de escritores; su categorización se basaría sencillamente en la recurrencia de ciertos rasgos temáticos y formales en los textos de quienes vivieron la experiencia de los campos de concentración.

En relación con esto último, es necesario profundizar igualmente en el carácter particular de los campos de concentración (Sánchez Zapatero, 2010: 46). Se podría plantear así la opción de extrapolar esta categoría a otros fenómenos históricos y sociales semejantes, como es el caso de los prisioneros de guerra o de los presos políticos, y sin embargo debe destacarse que los campos de concentración son una catástrofe sin comparación. A diferencia de los ejemplos mencionados, Sánchez Zapatero mantiene que cuando se habla del caso concentracionario "se ha

\footnotetext{
* Este trabajo es resultado de la investigación llevada a cabo bajo el patrocinio de una beca FPU concedida por el Ministerio de Educación, Cultura y Deporte.

${ }^{1}$ El término concentracionario proviene de la obra de David Rousset (2004).

${ }^{2}$ Vándor señala que son textos que pueden pertenecer "a géneros distintos: basta con pensar en algunos de los autores más afamados (P. Levi, Jean Améry, Kertész) para recordar libros en los que se mezclan lo autobiográfico, el estudio analítico y el ensayo, o bien la historia y la ficción -y todo es literatura" (2004: 126).
} 
de hacer referencia necesariamente a la aleatoriedad" (2010: 47). Esta aleatoriedad provoca la ausencia de al menos una legalidad que, aunque injusta o desproporcionada, justifique el estado del preso. En otras palabras, en esos casos ni siquiera hay ley que regule la circunstancia del condenado; el que está retenido en un campo pertenece así a una categoría diferente a la del ser humano. Los campos, añade Todorov, "representan el límite extremo de los propios regímenes totalitarios: la manifestación más intensa, la más concentrada, su quintaesencia" (2007: 292). En esa particularidad reside su consideración especial.

Cuando se habla de campos de concentración, por otro lado, resulta irremediable la alusión indirecta al Holocausto nazi. El hecho de que se trate del ejemplo paradigmático, no obstante, provoca que en el imaginario colectivo esta sea la única realidad concentracionaria existente. Por ejemplo, Vándor señala que se ha utilizado el nombre de Auschwitz como término genérico para el campo de concentración, lo que puede inducir a confusión teórica (2004: 127). El fenómeno de los campos de concentración, sin embargo, engloba un conjunto de acontecimientos históricos que va mucho más allá de la catástrofe nazi; por este motivo, el marco de la literatura concentracionaria no debe limitarse "a unas determinadas coordenadas espacio-temporales" (Sánchez Zapatero, 2011: 326). La realidad concentracionaria tiene un largo recorrido, y si bien no se ha hallado la misma cantidad de producción literaria en otras circunstancias similares como los Gulag rusos, debe quedar claro que esta forma va mucho más allá de una época y un contexto determinados, de tal manera que el análisis de este trabajo, en tanto que reflexión teórica, concierne a toda la literatura concentracionaria, por más que la mayoría de ejemplos remita al que es el acontecimiento más importante del pasado siglo.

Volviendo a la primera idea de este apartado, lo que caracteriza a este corpus de textos en contraposición a otros es el dominio absoluto de la forma y el tono testimonial. Como mantiene Sánchez Zapatero, la característica esencial que relaciona todos los textos concentracionarios "es la condición de testigo de sus autores" (2010: 93). Este tipo de textos en donde predomina la primera persona, forma esencial de la escritura concentracionaria, se ubica en un terreno muy próximo al de la literatura autobiográfica, en la medida en que el Yo es agente de los hechos que se narran en el texto. Sin embargo, el Yo que aparece en los textos concentracionarios se diferencia del Yo autobiográfico en su 
intención testimonial. El Yo de la literatura concentracionaria no habla solamente desde la individualidad, sino que también lo hace en nombre de un determinado colectivo, y es precisamente este hecho el que lo convierte en literatura, toda vez que va más allá de la mera revelación del Yo histórico al representar no una individualidad, sino un tipo de individuo.

Dentro de la literatura concentracionaria, hay una forma más problemática que el resto, como es el diario personal, que, con su evolución a lo largo del tiempo, adquiere un carácter privado que lo hace contrario, en apariencia, a toda posibilidad de testimonio. El diarista no puede tener una intención testimonial en tanto que sus páginas están dirigidas aparentemente al propio autor. Esta premisa, que opondría la relación no solo del diario personal con la literatura concentracionaria sino también con el propio concepto de literatura, es la que va a ser cuestionada en estas páginas, para ofrecer un análisis teórico del diario personal como texto literario vinculado a la literatura concentracionaria.

\section{La consideración testimonial del texto concentracionario}

El testimonio, en tanto que colindante con el texto histórico, se opone en apariencia a la definición de literatura que se sigue en estas páginas y que está vigente en la mayor parte de los estudios literarios. La literatura, desde esta perspectiva, "est una fiction: violà sa prèmiere définition structurale" (Todorov, 1987: 12). El carácter ficcional de la literatura, no obstante, no implica que formas como la autobiografía, la poesía o el ensayo se excluyan del sistema literario; el concepto de ficción no debe ser entendido solo desde un sentido restrictivo. Este no es equivalente al de simulación ni opuesto, por tanto, al de verdad; muy al contrario, la literatura se ubica en un terreno en donde carecen de sentido tales parámetros.

Entre las formas que se incluyen dentro del sistema literario se encuentra la del testimonio. Si bien su naturaleza propicia su tratamiento como material histórico, el testimonio hace mucho tiempo que ha pasado a formar parte de la literatura, dejando clásicos del género como $\mathrm{Me}$ llamo Rigoberta Menchú y así me nació la conciencia (2007), hasta el punto de que ha habido autores que han cuestionado la consideración antropológica e histórica de estos textos. Elzbieta Sklodowska, a este respecto, señala lo siguiente: 
[...] sería ingenuo asumir una relación de homología directa entre la historia y el texto. El discurso del testigo no puede ser un reflejo de su experiencia, sino más bien su refracción debida a las vicisitudes de la memoria, su intención, su ideología. [...] Así pues, aunque la forma testimonial emplea varios recursos para ganar en veracidad y autenticidad, el juego entre ficción e historia aparece inexorablemente como un problema (1982: 379).

El juego entre ficción e historia que cita Sklodowska aparece como un problema en los ámbitos en donde la verificabilidad del texto testimonial es importante: el terreno de la antropología, de la historia y de la ciencia. En literatura, sin embargo, lo que importa, a priori, no es la verificabilidad de un texto, sino su verosimilitud; se juzga la validez de un texto literario para presentarse a sí mismo como tal. En el caso que se ha puesto líneas más arriba, a propósito del testimonio de Rigoberta Menchú, el investigador David Stoll, en palabras de John Beverley (2002: 9), descubrió que varios episodios de los que la autora guatemalteca describía en su discurso no eran del todo exactos, y habían sido adornados por su imaginación. El testimonio de Rigoberta Menchú, de esta forma, fallaba como texto histórico; no así, a priori, como texto literario.

Ahora bien, dicho lo anterior, el testimonio también posee un condicionante de esta verosimilitud. Se trataría de una especie de pacto testimonial ${ }^{3}$, según el cual el lector acepta respetar los términos del autor para leer y creerse su obra. Javier Sánchez Zapatero (2010: 111) habla así de la ética del testigo para justificar el pacto testimonial que se da en la literatura concentracionaria. Este pacto, que justifica la lectura del texto literario-testimonial en términos históricos, remite al debate clásico en los estudios autobiográficos. Tal debate está protagonizado por la postura pragmática de Philippe Lejeune (1994), acuñador del pacto autobiográfico, según el cual el autor del texto firma un pacto de sinceridad con el lector, y el planteamiento deconstruccionista de Paul de Man (1991), del que se desprende la total independencia del texto respecto a la verdad de sus contenidos. A tenor de lo postulado por Lejeune, el texto de Menchú fallaría como texto autobiográfico y por lo tanto como testimonio, si bien Paul de Man mantiene que el texto es plenamente independiente de su autor y por lo tanto mantendría $s u$ verdad.

\footnotetext{
${ }^{3}$ Algunos autores hablan asimismo de un pacto moral, como es el caso de Loureiro (2001) y su concepción ética del texto autobiográfico.
} 
Tales posturas, sin embargo, son superadas décadas después por un autor como Pozuelo Yvancos, que sostiene la posibilidad de leer el texto autobiográfico desde una perspectiva conciliadora. Pozuelo (2004: 177) considera que el texto autobiográfico tiene un doble estatus: referencial y performativo. El texto autobiográfico sería capaz, al mismo tiempo, de mantener una correspondencia con el mundo real y de construir un Yo puramente textual, ficticio, sometido a las leyes concretas de la escritura. Esta lectura habilitaría tanto la lectura referencial como la lectura performativa del texto, y el testimonio, tratado en este caso, se podría leer como verdad y también como literatura, de tal modo que el texto concentracionario debería respetar las dos dimensiones mencionadas -la contractual de lo autobiográfico y la narrativa de lo literario- para poder conformarse como literatura concentracionaria y como testimonio, algo que el texto de Rigoberta Menchú -en tanto que, según dice Stoll, defrauda al lector y solo podría funcionar como fábula literariano hace.

\section{El diario y su origen testimonial}

Dentro de la literatura concentracionaria, destaca una forma autobiográfica como el diario personal. Si bien se ha visto que la literatura y el testimonio son formas de polémica conciliación, más aún lo son el diario personal y el testimonio, toda vez que el primero está escrito, al menos en origen, para el propio autor, no para su divulgación pública. Pese a ello, la escritura diarística es una de las formas que más repercusión y desarrollo ha tenido dentro de la literatura concentracionaria, de tal manera que debe tratarse desde la teoría el modo en que este diario escrito para uno mismo puede poseer, finalmente, una intención testimonial. Para ello, es aconsejable retroceder al origen de esta manifestación autobiográfica.

El diario personal no posee un origen claro ni una trayectoria definida. Precisamente esta naturaleza privada de la que se ha hablado impide que pueda establecerse un origen exacto del diario, en la medida en que muchos diarios personales han sido llevados a cabo en el anonimato. Pese a ello, el diario entendido desde una perspectiva moderna parece tener unos orígenes consensuados. Los principales autores coinciden en situar su origen a finales del siglo XVIII, con la aparición de la Revolución francesa y el nuevo orden democrático. Es esta la posición 
de Alain Girard (1996), quien destaca la aparición de la individualidad romántica como factor esencial para el desarrollo de la forma diarística. Según su teoría, por tanto, los primeros diarios personales se concibieron en torno a 1800 , no siendo publicados hasta décadas posteriores, tras la aparición del Diario íntimo (1839-1850) de Amiel. Otra corriente de autores, sin embargo, como es el caso de Antonio Dorta (1963), retrocede hasta el siglo XVII para encontrar la forma primigenia del diario en la cultura anglosajona. Dorta habla así de Samuel Pepys y otros diaristas ingleses como Swift o Wesley.

Más allá de establecer una teoría genética de la escritura diarística, interesa retroceder a las formas que anticiparon su desarrollo. Así, uno de los posibles orígenes se corresponde con los viejos diarios de navegación: el capitán del barco, o cualquier otro miembro del pasaje, anotaba en estos cuadernos la crónica del viaje, dando como resultados diarios "en los que normalmente está excluida la intimidad, pues es la intimidad algo que repele a la ciencia" (Trapiello, 1998: 33). La intención del diario de navegación, por lo tanto, no era otra que la de ofrecer un testimonio del viaje y registrar los sucesos fundamentales del día a día. Esta naturaleza testimonial, según Trapiello, ha pervivido de alguna manera en los diarios.

Tan interesante como este origen es el que apunta Anna Caballé; basada en los estudios de Amelang y Castillo Gómez, habla del "libro de cuentas" como precursor de la forma diarística. Este libro de cuentas funcionaba como registro de propiedad de la familia, y de ahí se deriva su carácter testimonial. Esta forma es precursora de una nueva forma de registro "más privada y sentimental, y apoyada en los estados de ánimo, de sus orígenes contables" (Caballé, 2015: 64).

De estos dos orígenes puede deducirse un elemento testimonial indiscutible en la formación y desarrollo del diario personal. Este elemento va perdiéndose inevitablemente a medida que la escritura diarística se adentra en los terrenos de lo personal, pero su naturaleza primigenia nunca termina de desaparecer.

Por otro lado, en la configuración del diario personal a principios del siglo XIX interviene un cambio epistemológico definitivo. Este cambio tiene que ver con el paso que sufre el diario personal del ámbito privado al público. En referencia a esto, Girard señala que el paso de lo privado a lo público, manifiesta "un cambio profundo en la concepción que la 
persona tiene de sí misma" (1996: 32). Este paso de lo privado a lo público fructifica con la aparición del citado Diario íntimo de Amiel. Curiosamente, es justo este diario el primero que recibe la apelación de íntimo, de lo que puede deducirse el carácter retórico de la etiqueta: el primer diario que accede a una dimensión pública y que, sin embargo, arrastra en su nombre esa consideración de privacidad. Como ejemplo, años después de Amiel, en 1897 Miguel de Unamuno publica su Diario intimo, una obra que, como su propio autor reconoce, está escrita con la intención de ser publicada. En esta línea, casi todos los diarios que se escriben a partir de la publicación de Amiel están producidos ya en un contexto en donde el diario puede ser concebido como una forma literaria (Picard, 1981).

Con la nueva dimensión del diario, el testimonio tal y como se entiende en la literatura concentracionaria-como producción de un autor cuya característica esencial es la de ser testigo- vuelve a tener sentido; porque el diarista confecciona, sin matices, su diario en atención a un lector y con una intención testimonial.

De estas dos circunstancias puede deducirse la consideración del diario como texto de carácter testimonial, posibilitando así el análisis de la escritura diarística como forma de la literatura concentracionaria.

\section{El carácter literario del diario personal}

La condición literaria de la escritura autobiográfica, no obstante, ha sido puesta en duda por numerosos teóricos, que entienden que su naturaleza referencial está en contra de la idiosincrasia ficcional de la literatura. En este artículo, se tiene en cuenta una definición de la literatura que considera la inevitable naturaleza ficcional del texto literario; eso no impide, sin embargo, concebir el texto autobiográfico como literario, incluso sin renunciar a su carácter referencial.

El modo en que se articula esta conjunción entre ficción y texto autobiográfico se ha desarrollado líneas más arriba. Como indicaba Pozuelo, el texto autobiográfico tiene un doble estatus referencial y performativo que por supuesto comparte la escritura diarística. ¿Cómo se lleva a cabo exactamente esto? Según nuestra postura, la escritura diarística se construye del mismo modo en que lo hace la ficción, y aunque tenga, efectivamente, un componente referencial, en la medida en que los 
hechos que narra se corresponden con la realidad, al estar construidos como un texto ficticio hace que puedan ser leídos como ficción. Esta idea la resume con mucho acierto Philippe Forest:

Cierta doxa crítica actual opone literatura testimonial y literatura de ficción: a un lado, la confesión; al otro, la fabulación. [...] Pero "lo vivido" no se distingue en absoluto de "lo ficticio" cuando se enuncia según las reglas de un mismo modelo narrativo. [...] Porque "vivido" y "virtual" descansan sobre la misma conjura ficcional de ese "real" donde lo imposible invita al sujeto literario a vislumbrar una forma posible de existencia (Forest, 2012: 221).

De esta manera, lo vivido es igual a lo ficticio cuando se formula con las reglas del modelo narrativo. En la misma definición de Forest se deduce la existencia de la llamada literatura testimonial. Esta, como se ha dicho, mantiene una naturaleza referencial y al mismo tiempo es literatura. Ello se explica gracias al espacio concreto que ocupa nuestra noción de literatura. Esta se ubica en un espacio en que las nociones de verdadero o falso pierden sentido. César Nicolás señala que "la semántica de lo autobiográfico responde a la ficción literaria, donde lo leído no es ni verdadero ni falso" (2004: 510). El diario personal, de esta forma, puede ser leído desde una perspectiva literaria hasta el punto de que da lugar a la consideración del llamado diario literario ${ }^{4}$.

A esta idea, sin embargo, queda añadirle un matiz muy importante que invalida toda la teoría deconstruccionista: el texto autobiográfico, aunque enunciado con las mismas técnicas que el texto ficcional puro, sí guarda una correspondencia con la realidad, de tal manera que cumple un pacto autobiográfico que, en caso de ser incumplido -porque se demuestre la falsedad de determinados sucesos narrados en él-, puede destruir la verosimilitud del texto.

Por otro lado, es interesante retroceder en nuestro análisis para volver a ver las relaciones entre diario y testimonio. En el primer epígrafe se hablaba de la diferencia entre el Yo autobiográfico y el Yo testimonial con relación a la colectividad que representaba el último en contraposición al primero. La propia Rigoberta Menchú, en el prólogo a su famoso testimonio, confesaba que lo narrado pertenecía a la "vida de todos. [...] Mi situación personal engloba la realidad de un pueblo"

\footnotetext{
${ }^{4}$ Concepto que he desarrollado en otro lugar (Luque Amo, 2016).
} 
(Burgos, 2007: 21). Pues bien, este carácter testimonial de la literatura concentracionaria, que la hace construir textos autobiográficos, representantes no de un individuo sino de una colectividad, también afecta al diario personal. De esta forma, la naturaleza íntima del diario personal pierde su fuerza en favor de un testimonio que no involucra solo al Yo diarístico. Puertas Moya describe este fenómeno:

[...] en épocas de persecución y enfrentamiento, la literatura íntima no sólo pretende dejar constancia testimonial, sino que busca esos ámbitos que se hurtan al dominio público, por lo que algunas modalidades autobiográficas (diarios o cartas, por ejemplo) se manifiestan como las vías más adecuadas para la expresión perentoria de un sentimiento que, siendo individual y particular, es prueba de lo que experimenta un colectivo humano (2003: 412).

Puertas Moya apunta al ámbito personal como la salida idónea del Yo que pretende dejar testimonio. Precisamente porque en el espacio público no se puede expresar este testimonio, el escritor busca lo personal para desarrollar su declaración; habría que concluir que esta es la característica principal del diario personal escrito en este ámbito. El Yo diarístico concentracionario, de esta forma, es un Yo que habla muchas veces en nombre de una colectividad, y esto lo hace situarse más cerca del espacio literario que el protagonista del diario convencional, en la medida en que la literatura es siempre el terreno de lo universal, en contraposición a lo individual. El personaje literario es así aquel que es capaz de representar un tipo, y al mismo tiempo subvertirlo, de tal modo que su individualidad pasa a ser universal y representa a todos los miembros del colectivo. El diario personal concebido en el ámbito concentracionario tendría, pues, una naturaleza eminentemente literaria, toda vez que, como testimonio, se construye de cara a un lector y conlleva una universalidad que el diario personal puro solo sugiere.

\section{El diario personal en la literatura concentracionaria}

Todo lo escrito conduce a integrar el diario personal dentro de la literatura concentracionaria. Una vez establecido el marco teórico, cabe preguntarse por la naturaleza de este tipo de diario. El más famoso asociado a la literatura concentracionaria es el Diario (2012) de Ana Frank. Un diario que, pese a no tratar la experiencia de los campos, debe ser 
englobado dentro de la literatura concentracionaria en tanto que, como indica Sánchez Zapatero:

el nivel de violencia latente que habita en ellos es equiparable al de los más míticos textos sobre los campos. [...] La consideración de estas obras como "pórtico" que permite comprender en su totalidad los textos concentracionarios viene avalada por el hecho de que muchos textos de campos comienzan narrando los cambios que su vida cotidiana experimentó antes de la deportación (2010: 172).

Analizable desde tal perspectiva, este Diario está sujeto a varias polémicas de orden pragmático. En primer lugar, su autoría suele ponerse en cuestión: la temprana edad de Ana Frank al redactar las notas de su diario, y el control de su padre Otto Frank, en calidad de editor, sobre las diversas partes de la obra, tienden a dibujar la obra publicada como un texto muy alejado de las notas iniciales. Más importante resulta la concepción de la propia autora, que en todo momento considera sus notas diarísticas como la base de una futura novela. Lo que se ha presentado de esta forma como el Diario es el compendio hecho por Otto Frank de las dos versiones del diario que deja de su hija. La primera versión, compuesta por las notas iniciales, sirve de base a Ana Frank para redactar la segunda versión, que es una narración novelizada a partir de los datos recogidos en su diario. Además, la primera versión, compuesta por los textos originales del diario, está narrada en clave epistolar. De todo esto puede deducirse que el texto resultante puede ser cuestionado desde un punto de vista testimonial, y que por ello debe considerarse esta obra como un sencillo pórtico de la literatura concentracionaria.

Un texto claramente testimonial es el Diario de Praga (1941-1942) de Petr Ginz (2006), que es el diario dejado por un joven judío cuando las tropas alemanas invaden Praga. En el diario de Ginz, a diferencia del de Ana Frank, puede encontrarse una escritura más apegada a la referencia extratextual, de tal manera que suelen predominar las entradas concisas y las anotaciones esporádicas. En este sentido, el Diario de Praga es un diario puro, si bien las entradas meramente testimoniales no impiden que una parte considerable esté constituida por pasajes más desarrollados desde un punto de vista narrativo, en los que a partir de la evolución textual del Yo puede acometerse una lectura literaria del dia- 
rio personal, lo que lo convierte en un texto perteneciente a la literatura concentracionaria.

Otro diario personal puramente testimonial, por otro lado, es el Diario de Helga, de Helga Weiss (2013). Esta cualidad se deduce del propio subtítulo del libro: Testimonio de una niña en un campo de concentración. La propia autora señala que intervención editorial hubiera falseado el sentido de los hechos y el diario "habría perdido la autenticidad y la fuerza del testimonio" (2013: 20). A pesar de esto, la obra no es otra cosa que una reescritura de los diarios originales, que Weiss unifica y corrige después de la Guerra para otorgarle unidad y coherencia al texto. De esto se deriva que sea un texto claramente literaturizado: el Yo individual en estos diarios se oculta en beneficio de un Yo colectivo que persigue, sobre todo, dar cuenta del destino universal de las víctimas del Holocausto. En el Diario de Helga, las imágenes propias del mundo concentracionario son múltiples y el tono torna a veces similar al encontrado en una crónica, en perjuicio de una intimidad que no fructifica. Esto último conduce precisamente a que el texto se muestra muy interesante desde un punto de vista literario y quizás no tanto desde una perspectiva autobiobiográfica.

Más cercano a la prosa autobiográfica, se encuentran los diarios de Max Aub (1994). El escritor, protagonista de una vida homérica, vivió en varios campos de concentración entre 1940 y 1942, episodio que recoge en sus Diarios. A diferencia de lo que sucede con los otros diarios, el de Max Aub no es una obra cerrada que verse sobre el hecho concentracionario, pues la recopilación de su obra diarística no se lleva a cabo con este único propósito. Es, tal vez por eso, un diario personal en el sentido estricto del término. Así, el periodo que abarca de 1940 hasta 1942 está compuesto de simples notas diarísticas. La estancia en los campos de concentración no le permite así desarrollar una escritura que se decanta por la forma breve, por el apunte, por la anotación. Es, por decirlo así, una escritura diarística pura, despojada del ornato al que conduce la narración ${ }^{5}$. A pesar de esto, es posible encontrar pasajes en donde el Yo diarístico se explaya hasta el punto de que el texto toma forma de narración autorreflexiva. Solo en esas partes el diario tiene interés para la literatura. Más allá de eso, las anotaciones testimoniales

\footnotetext{
${ }^{5}$ Barthes, en Diario de duelo, señala: "No quiero hablar por temor a hacer literatura [...], aunque de hecho la literatura se origine en estas verdades" (Barthes, 2009: 27).
} 
que pueblan estos años -1940 y 1941- sirven, sobre todo, como testimonio histórico, y deben ser abordadas desde los estudios históricos ${ }^{6}$.

En último lugar, resulta de gran interés el diario de una autora casi desconocida: Silvia Mistral, que en Diario de una refugiada española (2009) narra su salida en 1939 de la España republicana en dirección a Francia, en donde sobrevive seis meses. Como en casos anteriores, la autora no narra estrictamente desde los campos de concentración, pero sí desde una atmósfera cercana como es la de los campos de refugiados españoles en Francia. La relación entre este contexto y el concentracionario es ratificada por la propia autora: "Hemos querido escapar y ha sido imposible" (2009: 84). El diario de Silvia Mistral está construido con total y exclusiva voluntad de dejar testimonio de los sucesos acaecidos en torno al hecho concentracionario. El texto, así, es publicado capítulo a capítulo en 1939 por la revista mexicana Hoy, meses después de lo ocurrido ${ }^{7}$. El Diario, además, tiene diferencias con los ejemplos anteriores: para empezar, está dividido en capítulos que a su vez contienen las entradas fechadas, ofreciendo un marco narrativo a estas últimas. Este marco, no obstante, no es inocente, pues el tono de las páginas de Mistral es profundamente narrativo, hasta el punto de que puede leerse el Diario como una novela, tal y como se leía el Diario de Ana Frank. Esto último provoca que, desde el punto de vista teórico, el Diario resulte de sumo interés, en la medida en que es un texto puramente diarístico que además desarrolla las formas ficcionales del Yo, de tal manera que puede ser leído como literatura y, sobre todo, como literatura concentracionaria.

Hay, en definitiva, decenas de obras que pueden ser relacionadas con la modalidad diarística de la literatura concentracionaria. Es el caso de los diarios firmados por los niños judíos que testimoniaron el Holocausto, por poner un ejemplo. En este artículo no se pretende, sin embargo, exponer una bibliografía o una historiografía de esta modalidad, sino sencillamente plantear un acercamiento teórico que justifique su pertenencia al terreno literario. Para ello, bastan estos cinco diarios de los que se ha hecho eco este epígrafe. De las cinco obras mencionadas, se

\footnotetext{
${ }^{6}$ Aparte de no pocos relatos, cabe resaltar otro texto concentracionario aubiano: el poemario Diario de Djelfa (1944). Aunque no se trata estrictamente de un diario, y por eso no se incluye aquí, su estudio puede resultar de interés.

${ }^{7}$ La revista mexicana comienza a publicar sus entradas a partir de octubre de 1939, cuando la autora está ya asentada en México.
} 
pueden deducir los diferentes vínculos que el diario personal mantiene con la literatura, que van desde el diario claramente novelizado de Ana Frank o la reconstrucción literaria de Helga Weiss hasta los pasajes puramente documentales de Max Aub, que solo en ocasiones resisten una lectura literaria. Así, mientras que los dos primeros textos se enmarcarían en un terreno muy cercano a la autoficción, el último funcionaría como documento histórico. Las dos obras restantes, en cambio, como son el texto de Petr Ginz y el de Silvia Mistral, resumirían lo que en otro lugar (2016) he denominado diario literario, toda vez que se construyen como diarios personales que pueden ser leídos desde los dominios de la literatura.

Si alguien como Todorov ha dicho que "los campos son la culminación del principio del terror" (2007: 293), puede deducirse la trascendencia que llega a tener el hecho concentracionario y el surgimiento de una forma literaria que persigue el testimonio de los campos. Dentro de la literatura concentracionaria, cuya etiqueta no se cuestiona tanto como se asume la necesaria descripción de una manifestación literaria concreta, habita el diario personal analizado en estas páginas.

\section{Bibliografía}

Aub, Max. 1994. Diarios (1939-1972), Manuel Aznar Soler (ed.). Barcelona: Alba.

Austin, John L. 1970. Philosophical papers. Oxford: Oxford University Press. Barthes, Roland. 2009. Diario de duelo. Barcelona: Paidós.

Beverley, John. 2002. Prólogo a la segunda edición. En Beverley, John \& Achúgar, Hugo. 2002. La voz del otro: testimonio, subalternidad y verdad narrativa. Ciudad de Guatemala: Ediciones Papiro, 9-16.

Burgos, Elizabeth. 2007. Me llamo Rigoberta Menchú y así me nació la conciencia. México D.F.: Siglo XXI.

Caballé, Anna. 2015. Pasé la mañana escribiendo. Poéticas del diarismo español. Sevilla: Fundación José Manuel Lara.

Dorta, Antonio. 1963. Breve biografía del Diario íntimo. Barcelona: Labor.

Forest, Philippe. 2012. Ego-literatura, autoficción, heterografía. En Casas, Ana (ed.) La autoficción. Reflexiones teóricas. Madrid: Arco-Libros, 211236.

Frank, Ana. 2012. Diario. Barcelona: Debolsillo.

Ginz, Petr. 2006. Diario de Praga (1941-1942). Barcelona: Acantilado.

Girard, Alain. 1996. El diario como género literario. Revista de Occidente 182183: 31-38. 
Lejeune, Philippe. 1994. El pacto autobiográfico. Madrid: Megazul.

Loureiro, Ángel 2001. Autobiografía: el rehén singular y la oreja invisible. Anales de literatura española 14: 135-150.

Luque Amo, Álvaro. 2016. El diario personal en la literatura: teoría del diario literario. Castilla. Estudios de literatura 7: 273: 306.

Man, Paul de. 1991. La autobiografía como des-figuración. Anthropos: La autobiografía y sus problemas teóricos. Estudios e investigación documental 29: 113-118.

Nicolás, César. 2004. Autobiografía y ficción. En Hermosilla Álvarez, M. A. \& Fernández Prieto, C. Autobiografía en España, un balance. Madrid: Visor, 507-532.

Picard, Hans Rudolf. 1981. El diario como género entre lo íntimo y lo público. 1616: Anuario de la Sociedad Española de Literatura General y Comparada 4: 115-122.

Pozuelo Yvancos, José Manuel. 2004. Autobiografía: del tropo al acto de lenguaje. En Hermosilla Álvarez, M. A. \& Fernández Prieto, C. Autobiografia en España, un balance. Madrid: Visor, 173-182.

Puertas Moya, Ernesto. 2003. La escritura autobiográfica en el siglo XIX: el ciclo novelístico de Pío Cid considerado como la autoficción de Ángel Ganivet (Tesis Doctoral). Madrid: UNED - Departamento de Literatura Española y Teoría de la Literatura. [Base de datos Teseo]. https://www. educacion.gob.es/teseo/mostrarSeleccion.do

Rousset, David. 2004. El universo concentracionario. Barcelona: Anthropos.

Sánchez Zapatero, Javier. 2010. Escribir el horror. Literatura y campos de concentración. Barcelona: Montesinos.

Sánchez Zapatero, Javier. 2011. La representación de la experiencia concentracionaria: un caso de literatura universal. 1616: Anuario de la Sociedad Española de Literatura General y Comparada 1: 325-337.

Sklodowska, Elzbieta. 1982. La forma testimonial y la novelística de Miguel Barnet. Revista/Review Interamericana 12(3): 375-384.

Todorov, Tzvetan. 1987. La notion de littérature et autres essais. Paris: Seuil.

Todorov, Tzvetan. 2007. Frente al límite. México D.F.: Siglo XXI.

Trapiello, Andrés. 1998. El escritor de diarios. Madrid: Península.

Vándor, Jaime. 2004. Los campos en la literatura. Reflexiones y ejemplos de la narrativa concentracionaria. Anthropos 203: 125-138.

Weiss, Helga. 2013. El diario de Helga. Testimonio de una niña en un campo de concentración. Madrid: Sexto Piso. 